\title{
Need to Replace the Toxic Biocides for Safe Environment
}

\section{Ashish Chauhan ${ }^{1 *}$ and Jashwant Singh ${ }^{2}$}

${ }^{1}$ National Institute of Pharmaceutical Education and Research, Mohali, Punjab, India ${ }^{2}$ Indian Institute of Technology, Kanpur, India

\section{Introduction}

Environment safety is a major issue of concern to the scientists world over after witnessing the results of using toxic chemicals like DDT in the environment. DDT (di chloro di phenyl tri chloro ethane) is a colorless, crystalline, tasteless and odorless organo-chloride compound known for its insecticidal properties. It is a chemical with a long, unique, and controversial history. First, synthesized in 1874, DDT's insecticidal properties were not discovered until 1939. In the early years of world war second. DDT was used with great effect to control mosquitoes spreading malaria, typhus and other insect borne diseases among both military and civilian populations. After the war DDT was made available for use as an agricultural insecticide.

DDT is similar in structure to the pesticide dicofol and methoxychlor. It is nearly insoluble in water but has a good solubility in most organic solvents, fats, and oils. It does not occur naturally, but is produced by the reaction of chloral $\left(\mathrm{CCl}_{3} \mathrm{CHO}\right)$ with chloro benzene $\left(\mathrm{C}_{6} \mathrm{H}_{5} \mathrm{Cl}\right)$ in the presence of sulphuric acid, which acts as a catalyst. From 1950 to 1980 , DDT was extensively used in agriculture. Since DDT residue are lipophilic they tend to accumulate in the fatty tissues of the ingesting organism along the food chain. Almost all the food stuffs including processed foods have been shown to contain high level of DDT residues. High level of DDT and its metabolites have been detected in human adipose tissues, blood plasma, liver, brain, placenta and even in breast milk. It is reported to be a potential endocrine disruptor in both avian and mammals. Resulting egg shell thinning, impaired male reproductive ability and depict interference with sex hormones that causes cancer and many other nervous diseases. Along with the passage of the Endangered Species Act, the US ban on DDT is cited by scientists as a major factor in the comeback of the bald eagle (the national bird of the United States) and the peregrine falcon from near-extirpation in the contiguous United States. Because of its lipophilic properties, DDT has a high potential to bio-accumulate, especially in predatory birds.

Keeping in view, the serious malefic effects of the synthetic toxic chemicals we should emphasize on bio-insecticides and bio-pesticides. The striking feature of bio-pesticides is environment friendliness and easy biodegradability, thereby resulting in lower pesticide residues and largely avoiding pollution problems associated with chemical pesticides. Further, use of bio-pesticides as a component of Integrated Pest Management (IPM) programs can greatly decrease the use of conventional (chemical) pesticides, while achieving almost the same level of crop yield. However, effective use of bio-pesticides demands understanding of a great deal about managing pests especially by the end users. One such example is Neem (Azadirachta indica). Neem leaf tea can be used to control termites. Neem oil to protect beans against storage pests. We can get mosquito repellent from neem. It can be used to control scabies, nematodes even HIV and for animal care.
*Corresponding author: Ashish Chauhan, National Institute of Pharmaceutical Education and Research, Mohali, Punjab, India, Tel: 9464616773; E-mail: aashishchauhan26@gmail.com

Received April 13, 2015; Accepted April 15, 2015; Published May 10, 2015

Citation: Chauhan A, Singh J (2015) Need to Replace the Toxic Biocides for Safe Environment. J Textile Sci Eng 5: 194. doi:10.4172/2165-8064.1000194

Copyright: (c) 2015 Chauhan A, et al. This is an open-access article distributed under the terms of the Creative Commons Attribution License, which permits unrestricted use, distribution, and reproduction in any medium, provided the original author and source are credited. 